\title{
(2) OPEN ACCESS \\ Changing levels of local crime and mental health: a natural experiment using self-reported and service use data in Scotland
}

\author{
Gergő Baranyi $\mathbb{B}^{1},{ }^{1}$ Mark Cherrie, ${ }^{1}$ Sarah E Curtis, ${ }^{1,2}$ Chris Dibben, ${ }^{1}$ Jamie Pearce (1) ${ }^{1}$
}

- Additional material is published online only. To view please visit the journal online (http://dx.doi.org/10.1136/ jech-2020-213837).

${ }^{1}$ Center for Research on Environment, Society and Health, School of GeoSciences, University of Edinburgh, Edinburgh, UK

${ }^{2}$ Geography Department, Durham University, Durham, UK

\section{Correspondence to} Gergő Baranyi, Center for Research on Environment, Society and Health, School of GeoSciences, University of Edinburgh, Edinburgh EH8 9XP, UK; gergo.baranyi@ed. ac.uk

Received 28 January 2020 Revised 24 April 2020 Accepted 28 April 2020

\begin{abstract}
Background This study contributes robust evidence on the association between mental health and local crime rates by showing how changing exposure to small arealevel crime relates to self-reported and administrative data on mental health.
\end{abstract}

Methods The study sample comprised 112251 adults aged 16-60 years, drawn from the Scottish Longitudinal Study, a 5.3\% representative sample of Scottish population followed across censuses. Outcomes were individual mental health indicators: self-reported mental illness from the 2011 Census and linked administrative data on antidepressants and antipsychotics prescribed through primary care providers in the National Health Service in 2010/2012. Crime rates at data zone level (500-1000 persons) were matched to the participants' main place of residence, as defined by general practitioner patient registration duration during 2004/2006, 2007/2009 and 2010/12. Average neighbourhood crime exposure and change in area crime were computed. Covariateadjusted logistic regressions were conducted, stratified by moving status.

Results In addition to average crime exposure during follow-up, recent increases in crime (2007/2009-2010/ 2012) were associated with a higher risk of self-reported mental illness, among 'stayers' aged $16-30$ years $(\mathrm{OR}=1.11 ; 95 \% \mathrm{Cl} 1.00$ to 1.22$)$, and among 'movers' aged $31-45$ years $(O R=1.07 ; 95 \% \mathrm{Cl} 1.01$ to 1.13$)$. Prescribed medications reinforced these findings; worsening crime rates were linked with antidepressant prescriptions among young stayers $(\mathrm{OR}=1.09 ; 95 \% \mathrm{Cl}$ 1.04 to 1.14 ) and with antipsychotic prescriptions among younger middle-aged movers (OR=1.11; 95\% Cl 1.01 to 1.23).

Conclusion Changing neighbourhood crime exposure is related to individual mental health, but associations differ by psychiatric conditions, age and moving status. Crime reduction and prevention, especially in communities with rising crime rates, may benefit public mental health.

\section{INTRODUCTION}

Mental disorders are major contributors to the global disease burden and present the leading cause of disability among young adults. ${ }^{1}$ In high-income countries, the burden is even larger: one in six adults in the United Kingdom is affected by common mental disorders at any given time, ${ }^{2}$ causing direct and indirect costs that equate to over $4 \%$ of the national gross domestic product. ${ }^{3}$ Over and above individual biopsychosocial determinants, the physical and social environment where people live influences mental health. ${ }^{4-6}$
Residential areas with high levels of deprivation and social disorganisation tend to have more crime and violence, ${ }^{7} 8$ impacting mental health due to heightened risks of personal victimisation and witnessing crime, ${ }^{9}$ and through an ecological pathway by inducing stress and fear of crime. ${ }^{10}$ While the notion that neighbourhood-level crime is associated with selfreported symptoms and mental health service use has been confirmed in ecological, ${ }^{11}$ crosssectional $^{12}{ }^{13}$ and longitudinal ${ }^{14-16}$ studies, investigations examining spatial and temporal variation in exposure to crime are lacking. Crime is not randomly distributed; incidents in a small number of micro-geographic areas account for a large proportion of total crime, ${ }^{8}$ 12 which can be key to explaining the relationship with mental health. ${ }^{12}$

Individual exposure to residential characteristics may change as the surrounding area alters in response to political and other contextual influences (eg, revitalisation, gentrification, postindustrial decline), ${ }^{17}$ or through residential mobility by people moving to different areas. Increasing neighbourhood deprivation has been linked to distress among residents staying in the same area. ${ }^{18}$ Also, moving from high-poverty to low-poverty areas might be beneficial for mental health, as demonstrated in experimental ${ }^{19}$ and observational studies. ${ }^{20}$ While there is some evidence that rising crime can be detrimental to mental health, ${ }^{14} 15$ studies often use crime aggregated into large geographic units, which may lack the specificity to capture spatio-temporal variability in crime. ${ }^{12}$ Finally, not only may neighbourhood crime cause mental disorders, but people with disadvantaged background or with pre-existing health conditions might be more likely to move into higher crime areas. ${ }^{21}$

Since the 1990s, the national-level reported crime rate has dropped in Scotland; however, the reductions have not been uniform between communities, ${ }^{8}$ providing an opportunity to use the spatio-temporal variation in crime as a natural experiment. ${ }^{14}$ To address this research gap, we investigated how individual self-reported mental illness and prescribed psychotropic medications related to increasing neighbourhood crime levels, taking into account residential mobility. Moreover, we aimed to identify demographic groups whose mental health seemed most vulnerable to crime effects, where prevention and service development might be particularly beneficial. 


\section{METHODS}

\section{Sample}

Data were drawn from the Scottish Longitudinal Study (SLS), a $5.3 \%$ nationally representative sample of the Scottish population. The SLS includes individuals selected on the basis of 20 semirandom birthdates and present in any of the 1991, 2001 and 2011 Censuses. $^{22}$ For this study, a subsample of $>126000$ was extracted, including individuals present at both the 2001 and 2011 Censuses and aged between 16 and 60 years in 2001. We applied age restrictions because psychopharmacological treatment among older adults may be less likely to be initiated by a mental disorder. ${ }^{16}{ }^{23}$ Individuals were excluded if living in communal establishments (eg, nursing homes) in 2001 or 2011 (1.0\%) or having missing values for the covariates $(10.5 \%)$. Area-level indicators of crime were linked to SLS participants using residential localities and dates of their registration with a general practitioner (GP). Healthcare administrative data were linked to participants based on unique personal identifiers (figure 1).

\section{Measures}

Mental health indicators

Mental health was measured using information on self-reported mental illness and prescribed medications. In 2011, all census respondents were asked whether they had '... conditions which have lasted, or are expected to last, at least 12 months?', with various response categories including 'mental health condition', taken here to indicate self-reported mental illness.

NHS administrative data on prescriptions for antidepressants (British National Formulary 4.3) and antipsychotics (British National Formulary 4.2) were derived from the Scottish National Prescription Information System, which covers all NHS Scotland prescriptions, prescribed, dispensed and reimbursed in the community setting. ${ }^{24}$ Antidepressants are mainly used to treat moderate-to-severe depression and in some cases anxiety disorders. At low dosage ( $\leq 30 \mathrm{mg}$ per day), amitriptyline and nortriptyline are often prescribed for neurological conditions, so these low-dose prescriptions were excluded from our study. ${ }^{25}$ Antipsychotics are principally used to treat psychotic and related disorders; however, severe anxiety can be also treated with them in the short term. ${ }^{25}$ Individuals with at least six prescriptions for antidepressants or antipsychotics in 2010/2012 were defined as cases. ${ }^{16}$

Self-reported mental health and prescribed medications are not available prior to 2009. To control for mental illness at baseline, psychiatric inpatient service use in 2001/2003 for substance use, psychotic, mood and neurotic disorders (ICD-10 codes: F10F48) from the Mental Health Inpatient \& Day Case dataset (Scottish Morbidity Records, SMR04) of NHS Scotland were linked to SLS. ${ }^{26}$

\section{Neighbourhood crime}

The Scottish Index of Multiple Deprivation (SIMD) includes a domain on local crime and is available for 6505 Scottish data zones, each comprising approximately 500-1000 residents. The crime domain aggregates police recorded and geo-referenced crimes and offences (eg, assault, crimes of violence, domestic housebreaking, drug offences and vandalism) throughout the preceding financial year. ${ }^{27}$ The Scottish Government applies disclosure control in low-crime areas by suppressing exact crime counts. To approximate missing values, we first ordered data zones by their non-suppressed crime ranks, assigned 0 crime into the lowest ranked unit and used linear interpolation to estimate suppressed numbers. Finally, crime rates per 1000 persons were computed based on population estimates. SIMD 2006 (first release), 2009 and 2012 provided longitudinal information on crime with consistent data zone boundaries (see changes in crime levels for Glasgow City in figure 2).

To link neighbourhood crime to SLS members, we used data on places of residence from the NHS GP registration database, holding records on patient registrations with GPs from 2000 onwards. $^{28}$ The SLS team derived for each participant the residential history comprising all residential data zones and dates of the changes recorded during the study. We assigned each SIMD crime release to a 3-year time interval (2004/2006 for SIMD 2006, 2007/2009 for SIMD 2009 and 2010/2012 for SIMD 2012), extracted for each participant the main residential data zone where the participants were

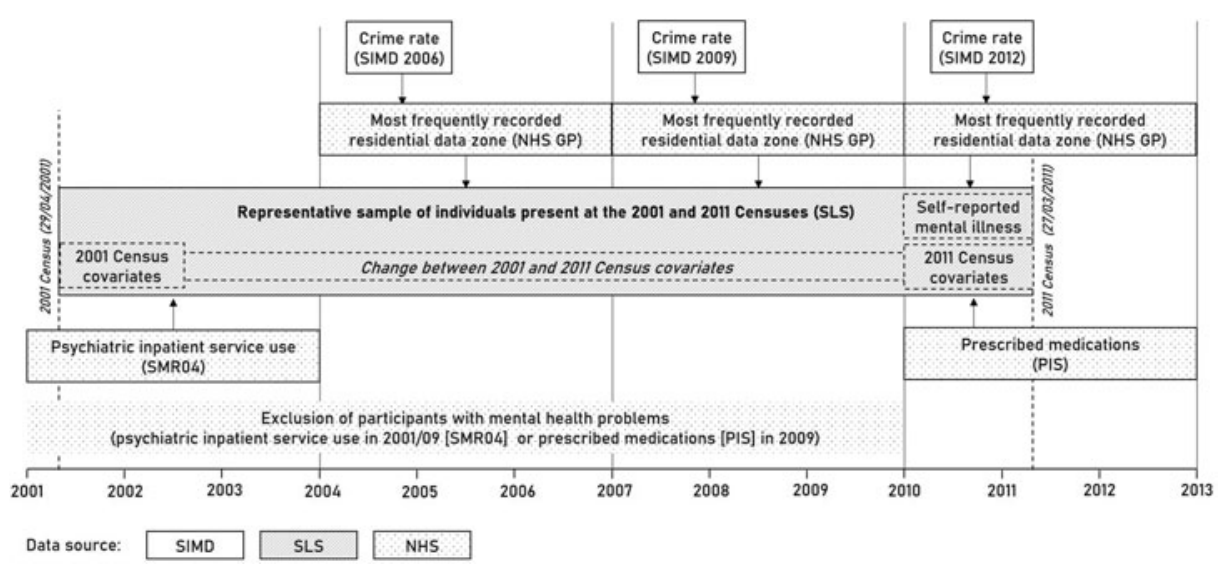

Figure 1 Operationalising crime, covariate and mental health variables using longitudinal data linkage in Scotland (2001-2013). Crime rates reported in the 2006/2009/2012 Scottish Index of Multiple Deprivation (SIMD) were linked to the Scottish Longitudinal Study (SLS) by using the residential data zone where SLS members were registered for the longest time during 2004/06, 2007/09 and 2010/12. Residential location was derived from records of the National Health Service (NHS) general practitioner (GP) registration database. Mental health service use within the NHS system was extracted from the Scottish National Prescription Information System (PIS) and from the Scottish Morbidity Records (SMR04), and information was linked to SLS participants using unique personal identifiers. For sensitivity analysis, participants with any records of mental health service use between 2001 and 2009 (SMR04 \& PIS) were excluded from the sample. 


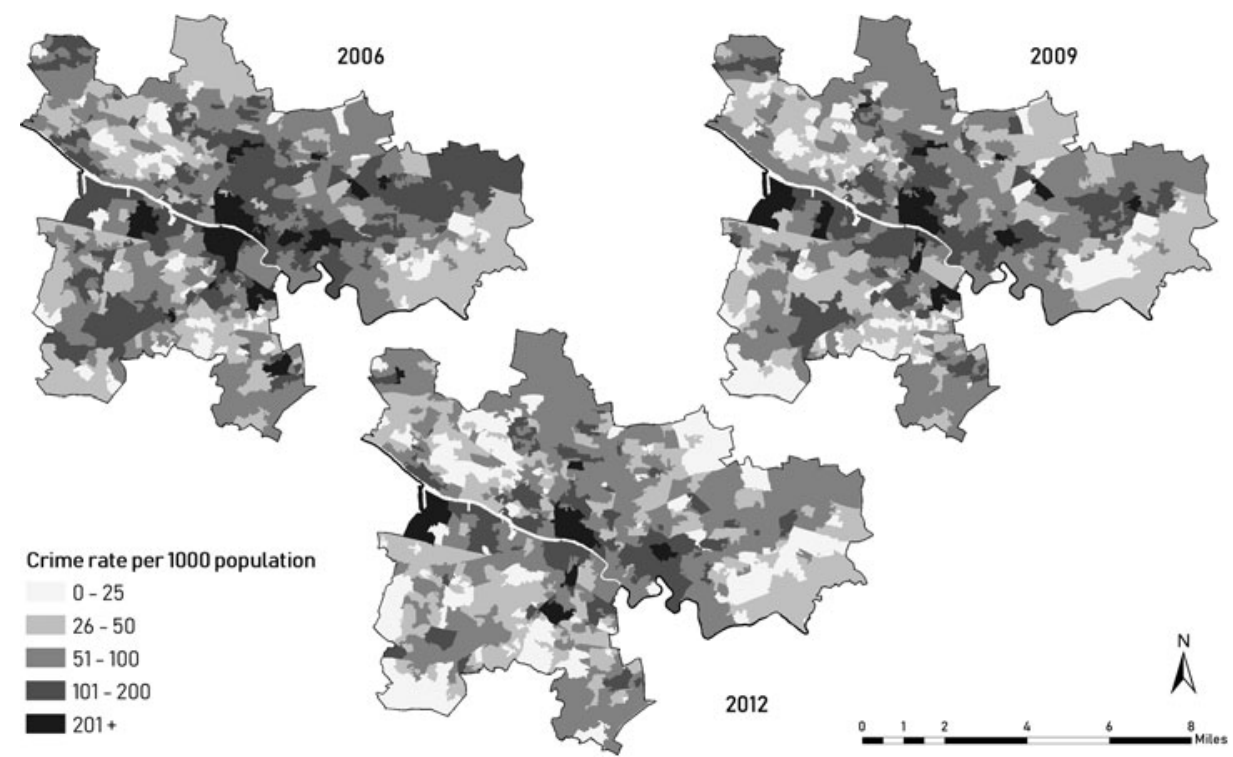

Figure 2 Crime rates per 1000 population in Glasgow City, Scotland, as reported in the 2006, 2009 and 2012 Scottish Index of Multiple Deprivation.

registered for the longest time within these three intervals and linked the participants to their respective crime rates. Finally, we stratified the sample into subsets, comprising individuals for whom the main residential data zone did not change during the study (stayers), changed between 2007/ 2009 and 2010/2012 (recent movers) and changed between $2004 / 2006$ and 2007/2009 (past movers).

\section{Covariates}

Covariates were derived from the 2001 and 2011 Censuses. Age and sex, extracted from both censuses, were reviewed for consistency before inclusion. Baseline variables were derived from the 2001 Census and classified as follows: ethnicity (white, non-white); highest educational attainment (no qualification, levels 1-4); social class based on occupation (I/II, IIIN, IIIM, IV, V); employment status (employed, unemployed, retired, out of labour force, student); marital status (married, single, separated, divorced, widowed); living status (alone, with others); and limiting long-term illness (yes, no). For time-variant covariates, we computed binary change indicators between censuses (change, no change): gained higher level of education; separated, divorced or widowed; started to live alone; and became unemployed or left labour force. There is no consistent social class measure in 2001 and 2011 due to differences in census questions/codings; therefore, we included also the 2011 social grade variable (AB, C1, $\mathrm{C} 2, \mathrm{D}, \mathrm{E})$ in the models. A detailed description of the covariates is in Supplementary Table 1.

\section{Statistical analysis}

While repeatedly measured predictors were available, outcomes were only assessed at the end of the study. To preserve the longitudinal nature of the data, for each participant, we calculated summary measures ${ }^{29}$ of neighbourhood crime by decomposing average exposure during follow-up and change in exposure to crime. For average crime exposure $(\bar{x})$, first the arithmetic mean of the crime rates was calculated and then log-transformed in order to minimise the effect of extreme outliers and right-skewed distribution (equation 1). Change in crime exposure variables $\left(x_{\Delta}\right)$ was computed as the standardised difference between the person's average of crime exposure and the crime rates of places they lived in 2004/2006 or 2010/ 2012, with positive values expressing increasing rates and negative values expressing decreasing rates (equations 2,3 ). While average crime rates were related to long-term differences between individuals, change in crime indicated withinindividual variation in exposure.

$$
\begin{gathered}
\bar{x}=\log 10\left(\frac{x_{2004 / 06}+x_{2007 / 09}+x_{2010 / 12}}{3}\right) \\
x_{\Delta 2004 / 06}=s d r\left(\frac{x_{2004 / 06}+x_{2007 / 09}+x_{2010 / 12}}{3}-x_{2004 / 06}\right) \\
x_{\Delta 2010 / 12}=s d r\left(x_{2010 / 12}-\frac{x_{2004 / 06}+x_{2007 / 09}+x_{2010 / 12}}{3}\right)
\end{gathered}
$$

We fitted logistic regression models with clustered robust estimations, allowing SEs varying between the 32 Scottish local authorities ${ }^{16}$ as recorded at the time of outcome measurement. All models included average and change variables. In the first set of models, we controlled for sex, age and age-squared. The second model additionally adjusted for all 2001 covariates (ethnicity, education, social class, employment, marital status, living status, long-term illness) and for psychiatric inpatient service use in 2001/2003. Finally, in the fully adjusted model, we additionally controlled for changing individual circumstances between 2001 and 2011 (gained higher level of education; separated, divorced or widowed; started to live alone; became unemployed or left labour force) and for social grade in 2011. Models were run separately for those identified as residential 'movers' and 'stayers'. For past movers, we included the 2004/2006 $\left(x_{\Delta 2004 / 06}\right)$ and for stayers and recent movers the 2010/2012 change variable $\left(x_{\Delta 2010 / 12}\right)$. As the effect of crime might differ by age, ${ }^{16}$ models were presented separately in young adulthood 
(aged 16-30 years in 2001), younger middle adulthood (aged 31-45 years) and older middle adulthood (aged $46-60$ years).

The following sensitivity analyses were carried out. (1) Using the same method as for crime, we extracted data zone income deprivation from the 2006/2009/2012 SIMDs, calculated standardised average and standardised change of deprivation and imputed them in the final models, in order to test whether crime change had a robust effect over and above income deprivation. (2) Instead of extracting the main residential data zone in each interval, we restricted the stayer subsample to those who lived at the same location during all 108 months of the study. (3) In order to strengthen the causal perspective, we excluded from the sample all individuals who were likely to have long-standing mental health conditions prior to outcome measurement, indicated by those who had any psychiatric admission in 2001/2009 and any psychotropic prescription in 2009 (medication data are

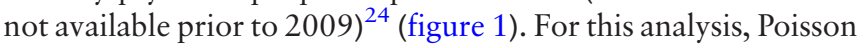
regression with clustered robust SEs estimated the incidence rate ratio (IRR) of crime on mental ill health.

\section{RESULTS}

Out of 112251 Scottish adults, 72\% were classified as 'stayers', $14 \%$ as 'past movers' and $14 \%$ as 'recent movers' (table 1). At the end of the study, $5.0 \%$ of the sample reported having a long-term mental illness, $14.4 \%$ had been prescribed at least six rounds of antidepressants and $1.2 \%$ had at least six rounds of antipsychotic prescriptions. The prevalence of mental health outcomes differed across moving status and age cohorts, with higher rates among middle-aged adults and recent movers, especially for antipsychotics (Supplementary Table 2). For the total sample, the average neighbourhood crime rate was 44.2 per 1000 persons $(\mathrm{SD}=47.1)$; the crime rate dropped by $5.7(\mathrm{SD}=30.3)$ between $2004 / 2006$ and $2007 / 2009$ and by 6.9 per 1000 persons $(S D=25.5)$ between $2007 / 2009$ and 2010/2012. Young adults and recent movers were exposed to higher neighbourhood crime on average, but they also experienced a larger drop in exposure (Supplementary Table 3).

\section{Self-reported mental illness}

In the fully adjusted models, in addition to a strong association with higher average crime exposure $(\mathrm{OR}=1.51 ; 95 \% \mathrm{CI} 1.35$ to 1.68), $1 \mathrm{SD}$ increase in crime was associated with $4 \%$ higher odds of reporting mental illness (95\% CI 1.02 to 1.06). In the models stratified by moving status, crime increase remained significant only among recent movers $(\mathrm{OR}=1.04 ; 95 \% \mathrm{CI} 1.01$ to 1.07$)$ (table 2). After stratifying by age cohorts, the association with average crime exposure was stronger among younger individuals $(\mathrm{OR}=1.84 ; 95 \%$ CI 1.54 to 2.21$)$. Moreover, $1 \mathrm{SD}$ increase in crime exposure elevated the odds of self-reported mental illness by $11 \%(95 \%$ CI 1.00 to 1.22 ) among young stayers (due to change in local crime rates) and by $7 \%$ (95\% CI 1.01 to 1.13 ) among recently moved younger middle-aged adults (table 3 ).

\section{Prescribed medications}

Higher average crime exposure increased the risk of having been prescribed at least six rounds of antidepressants $(\mathrm{OR}=1.27 ; 95 \%$ CI 1.20 to 1.34 ) or antipsychotics (OR=1.25; $95 \%$ CI 1.06 to 1.47), with associations being stronger among recent movers. Change in crime exposure, however, only remained significant for antipsychotics in the fully adjusted models $(\mathrm{OR}=1.06 ; 95 \%$ CI 1.01 to 1.12) (table 2). When exploring association by age
Table 1 Individual characteristics among the sample of 112251 Scottish adults (\%)

\begin{tabular}{|c|c|c|c|}
\hline Variable & & Value & $\%$ \\
\hline \multirow{3}{*}{$\begin{array}{l}\text { Moving } \\
\text { status }\end{array}$} & & Stayer (2004/2006-2010/2012) & 72 \\
\hline & & Past mover (2004/2006-2007/2009) & 14 \\
\hline & & Recent mover (2007/2009-2010/2012) & 14 \\
\hline \multirow{34}{*}{$\begin{array}{l}2001 \\
\text { covariates }\end{array}$} & Sex & Male & 47 \\
\hline & & Female & 53 \\
\hline & Age cohorts & $16-30$ & 27 \\
\hline & & $31-45$ & 40 \\
\hline & & $46-60$ & 33 \\
\hline & Ethnicity & White & 99 \\
\hline & & Non-white & 1 \\
\hline & $\begin{array}{l}\text { Highest educational } \\
\text { attainment }\end{array}$ & No qualifications & 29 \\
\hline & & Level 1 & 28 \\
\hline & & Level 2 & 16 \\
\hline & & Level 3 & 8 \\
\hline & & Level 4 & 20 \\
\hline & $\begin{array}{l}\text { Social class based on } \\
\text { occupation }\end{array}$ & $\begin{array}{l}\text { I/II—Professional, managerial and } \\
\text { technical occupations }\end{array}$ & 33 \\
\hline & & IIIN-Skilled non-manual occupations & 24 \\
\hline & & IIIM-Skilled manual occupations & 19 \\
\hline & & IV_-Partly skilled occupations & 15 \\
\hline & & V-Unskilled occupations & 6 \\
\hline & & Other & 4 \\
\hline & Employment status & Employed & 73 \\
\hline & & Unemployed & 4 \\
\hline & & Student & 6 \\
\hline & & Retired & 2 \\
\hline & & Out of labour force & 15 \\
\hline & Marital status & Single & 33 \\
\hline & & Married & 55 \\
\hline & & Separated & 4 \\
\hline & & Divorced & 7 \\
\hline & & Widowed & 1 \\
\hline & Living status & Alone & 11 \\
\hline & & With others & 89 \\
\hline & Long-term illness & No & 87 \\
\hline & & Yes & 13 \\
\hline & $\begin{array}{l}\text { Psychiatric inpatient } \\
\text { service use in 2001/ } \\
2003\end{array}$ & No & 99 \\
\hline & & Yes & 1 \\
\hline \multirow[t]{5}{*}{$\begin{array}{l}2011 \\
\text { covariate }\end{array}$} & Social grade & $\begin{array}{l}\mathrm{AB} \text { - Higher or intermediate } \\
\text { managerial, administrative or } \\
\text { professional grade }\end{array}$ & 21 \\
\hline & & $\begin{array}{l}\text { C1-Supervisory, clerical and junior } \\
\text { managerial, administrative and } \\
\text { professional grade }\end{array}$ & 31 \\
\hline & & C2-Skilled manual workers & 25 \\
\hline & & $\begin{array}{l}\text { D-Semiskilled and unskilled manual } \\
\text { workers }\end{array}$ & 22 \\
\hline & & $\begin{array}{l}\text { E-State pensioners, casual and lowest } \\
\text { grade workers, unemployed with state } \\
\text { benefits only }\end{array}$ & 3 \\
\hline
\end{tabular}




\begin{tabular}{|c|c|c|c|}
\hline Variable & & Value & $\%$ \\
\hline \multirow{8}{*}{$\begin{array}{l}2001-2011 \\
\text { change } \\
\text { indicators }\end{array}$} & Education & No change & 77 \\
\hline & & $\begin{array}{l}\text { Gained education between } 2001 \text { and } \\
2011\end{array}$ & 23 \\
\hline & Employment & No change & 95 \\
\hline & & $\begin{array}{l}\text { Became unemployed or left labour force } \\
\text { between } 2001 \text { and } 2011\end{array}$ & 5 \\
\hline & Marital status & No change & 93 \\
\hline & & $\begin{array}{l}\text { Separated, divorced or widowed } \\
\text { between } 2001 \text { and } 2011\end{array}$ & 7 \\
\hline & Living status & No change & 91 \\
\hline & & $\begin{array}{l}\text { Started to live alone between } 2001 \text { and } \\
2011\end{array}$ & 9 \\
\hline
\end{tabular}

Source: Scottish Longitudinal Study.

Note: Percentages are presented in whole numbers to avoid risk of disclosure; they may not sum to $100 \%$ because of rounding errors.

cohorts, models of prescribed medications reinforced the findings for self-reported mental illness (table 3): 1 SD increase in crime exposure among young stayers increased the odds of antidepressant prescriptions by $9 \%$ (95\% CI 1.04 to 1.14 ); among younger middle-aged movers, it increased the odds of antipsychotic prescriptions by $11 \%$ (95\% CI 1.01 to 1.23$)$.

\section{Sensitivity analyses}

After further adjustment for income deprivation, associations with average crime exposure only remained significant among older middle-aged stayers for antipsychotics and among young stayers for self-reported mental illness. Associations with change in exposure to crime were substantially attenuated for self-reported mental illness; however, they did not materially change for antidepressant and antipsychotic prescriptions (Supplementary Table 4). Findings on individuals staying all 108 months of the study at the same location reinforced that young adults were more vulnerable to increasing crime rates, with elevated risk of self-reported mental illness and antidepressant prescriptions (Supplementary Table 5). Finally, after excluding participants with mental health service use between 2001 and 2009, the prevalence of self-reported mental illness, antidepressant and antipsychotic prescriptions during 2010/2012 dropped with 80\%, 74\% and $92 \%$, respectively; drops in cases were particularly pronounced among middle-aged adults. The findings in this reduced sample confirmed previous associations for antidepressant medications among young stayers (IRR $=1.12 ; 95 \%$ CI 1.04 to 1.21 ). For antipsychotics, increasing crime exposure among young stayers significantly predicted prescriptions (IRR $=1.59$; 95\% CI 1.07 to 2.37 ), while the substantial drop in cases precluded analyses among movers (Supplementary Table 6).

\section{DISCUSSION}

This study provides a longitudinal perspective on the association between long-term average neighbourhood crime exposure and recent changes in crime and mental health in Scotland, using a natural experimental framework. Associations between average crime exposure and self-reported mental illness were twice as strong as for prescriptions and were mainly driven by relationships for the youngest age group. Recent increases in crime rates were related to mental health in two population subgroups: for self-reported mental illness and antidepressants among young adults staying in the same neighbourhood and for self-reported mental illness and antipsychotics among recently moved younger middle-aged adults. Sensitivity analyses reinforced the findings on antidepressants, but they challenged the causal perspective for antipsychotics.

This study extends the literature on the longitudinal relationships between neighbourhood crime and mental health, ${ }^{14-16}$ by estimating the link for self-reported versus service use outcomes, and in different age cohorts. Stronger association between average crime exposure and self-reported mental illness, in comparison to prescribed medications, may reflect how the former variable was measured. Self-reported mental illness might capture more serious and long-standing problems and thus had a lower prevalence than antidepressant prescriptions. It is also plausible that using psychotropic medications underestimated the association with crime by not fully capturing affected individuals from lower socioeconomic groups ${ }^{2}$ and including prescriptions not related to mental illness. ${ }^{25}$ Moreover, while the gap between mental health need and treatment is disproportionately large among young adults with low use of medications, ${ }^{2}$ they are more often victims of crime. ${ }^{30}$ This may explain the stronger links between crime exposure and self-reported mental illness in this cohort.

In comparison to average neighbourhood crime exposure, changes in individual exposure are less likely to be affected by residual confounding and may strengthen the causal evidence between exposure and outcome. Associations with increasing crime were evident in younger age, confirmed by both selfreported and medication data. Because of higher frequency of victimisation, ${ }^{30}$ young adults remaining in the same neighbourhood may be more vulnerable to increasing crime in their locality, linked to mental health conditions treated with antidepressants. Sensitivity analyses confirmed this link by supporting that the causation hypothesis ${ }^{31}$ may provide a suitable explanation for the neighbourhood-level crime and depression association.

Associations with changing crime exposure for antipsychotic prescriptions were more complex. After excluding individuals with pre-existing psychiatric conditions, the previously robust association among movers could not be estimated because of the large drop in cases. It is plausible that findings among middleaged individuals (for whom the highest incidence rate of firstepisode psychosis in young adulthood has already passed) ${ }^{32}$ reflect selective migration into higher crime areas related to preexisting severe mental disorders. ${ }^{21}$ Moreover, the increased risk of antipsychotic medication among young adults staying in the same area may require further exploration, as there is evidence suggesting that growing up in high-crime neighbourhoods may increase the risk of presenting psychotic symptoms through increased social stress and crime victimisation. ${ }^{33} 34$

This longitudinal data linkage study benefitted from a large and representative sample, covering the entire country with very low attrition rates. ${ }^{22}$ The NHS is (effectively) universally used in Scotland and psychotropic prescriptions were routinely collected with an exceptional completeness $195 \%$ of reimbursed prescriptions within NHS Scotland are captured with unique personal identifiers). ${ }^{24}$ However, several limitations have to be considered. First, while the NHS GP registration database contains residential localities with high accuracy, the reliability of the data might differ across age and clinical groups. Second, in Scotland, only 40\% of crimes are reported to the police, ${ }^{30}$ which may introduce bias to our findings. Third, outcomes were not available prior to 2009, precluding more robust statistical analyses (eg, fixed-effects models). ${ }^{14}$ Finally, self-reported mental illness and 


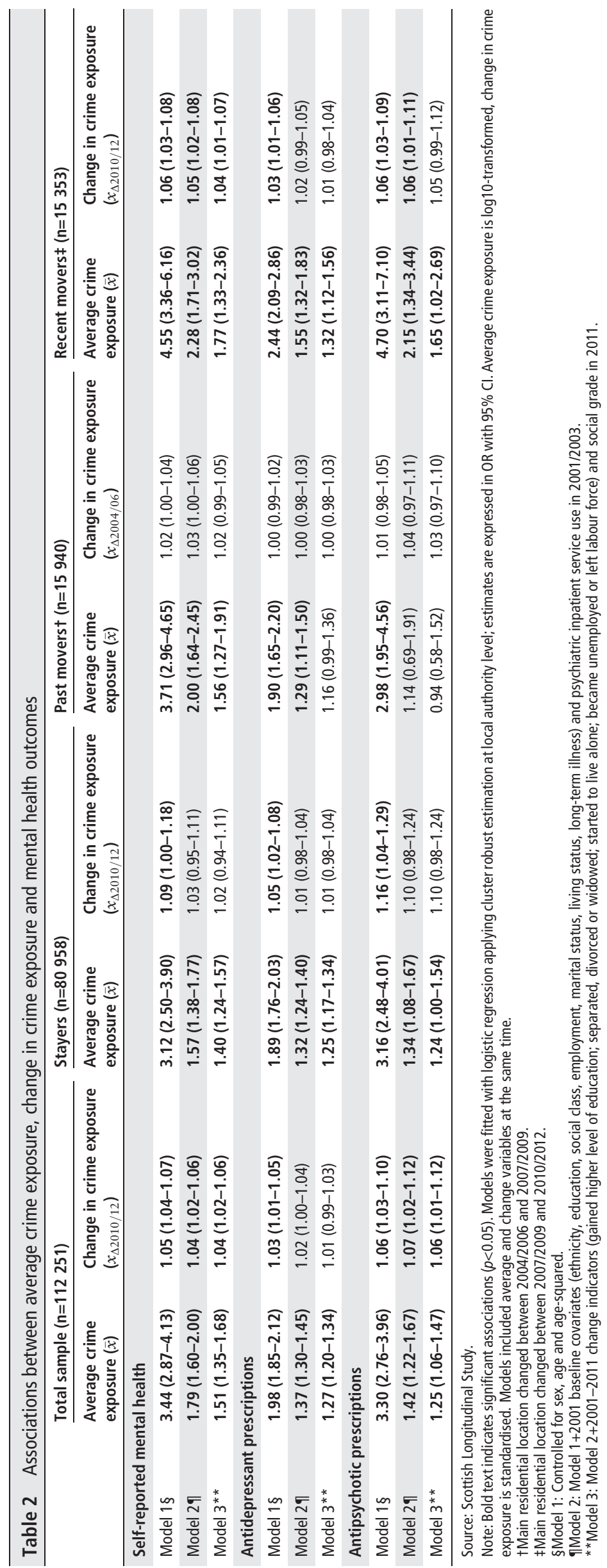




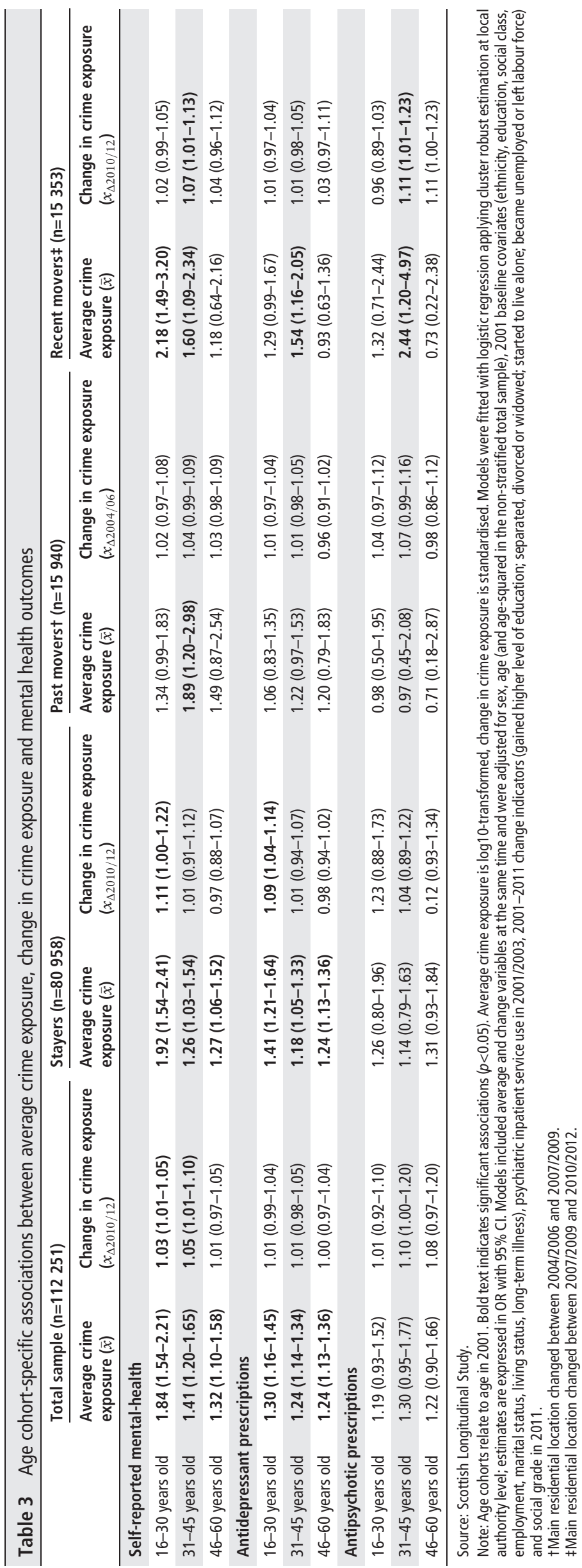


prescription data cannot be directly linked to psychiatric conditions; further studies with specific diagnoses are required to break down the neighbourhood crime-mental health relationship.

In conclusion, neighbourhood-level crime is a significant determinant of mental health and requires system-based actions. Crime reduction through neighbourhood interventions ${ }^{35}$ and spatially targeted policing ${ }^{36}$ may be beneficial for population mental health, particularly for young adults. Delivering mental health promotion for young people in high-crime areas, for example, school-based preventions ${ }^{37}$ and indicative prevention for high-risk individuals, ${ }^{38}$ as well as allocating services (eg, early psychosis programmes) ${ }^{39}$ to the vicinity of high-crime areas, may improve mental health and reduce the associated societal and economic burden.

\section{What is already known on this subject}

- Living in a high-crime area is related to mental health problems, but there are very few longitudinal studies using repeated measurements of small area-level crime rates.

- There is little research on whether this relationship differs by moving status, psychiatric conditions or age groups.

\section{What this study adds}

- For young adults staying in the same neighbourhood, increasing crime rates in their residential area were positively associated with self-reported mental illness and antidepressant prescriptions.

- Among recently residentially mobile younger middle-aged adults, moving to higher crime areas was associated with greater risk of self-reported mental illness and antipsychotic prescriptions; these findings were likely explained to some extent by health selective migration.

- Neighbourhood interventions, targeted policing and delivering mental health preventions and services in highcrime areas may help to reduce inequalities in mental health.

Twitter Jamie Pearce @jamieOpearce and Gergő Baranyi @GBaranyi

Acknowledgements The help provided by the staff of the Longitudinal Studies Centre Scotland (LSCS) is acknowledged. The LSCS is supported by the ESRC/IISC, the Scottish Funding Council, the Scientists Office and the Scottish Government. Census output is Crown copyright and is reproduced with the permission of the Controller of HMSO and the Queen's Printer for Scotland. The authors alone are responsible for the interpretation of the data. The authors also acknowledge the help provided by the electronic Data Research and Innovation Service (eDRIS) team, part of NHS National Services Scotland. The authors thank Dr Niall H. Anderson for his feedback on the statistical approach.

Contributors GB designed the study, conducted data analyses, interpreted the results and prepared the first draft. JP and CD participated in the study design, in the interpretation of the findings and commented on the manuscript. MC and SEC contributed to the interpretation and revised the manuscript.

Funding This work was supported by the European Union's Horizon 2020 research and innovation programme under the Marie Skłodowska-Curie grant agreement (LONGPOP — Methodologies and Data Mining Techniques for the Analysis of Big Data Based on Longitudinal Population and Epidemiological Registers (grant number 676060)). This research also benefitted from the support of the Economic and Social Research Council, UK (grant award ES/P008585/1).

Competing interests None declared.

Patient consent for publication Not required.

Ethics approval Ethical approval for the research was given by the SLS data governors, the Public Benefit and Privacy Panel for Health and Social Care, NHS
Scotland (application number eDRIS 1516-0398) and the Research Ethics and Integrity Committee, University of Edinburgh (GeoSciences_2018_189).

Disclaimer This publication reflects only the author's view and that the Research Executive Agency is not responsible for any use that may be made of the information it contains.

Data sharing statement The data used in this research are publicly not available, but may be accessible for scientific and statistical purposes after a successful application process (https://sls.Iscs.ac.uk/). The researcher has access to anonymised data in secure settings controlled by SLS. Results released for publication are carefully monitored to avoid any risk of disclosure about individuals.

Provenance and peer review Not commissioned; externally peer reviewed.

Open access This is an open access article distributed in accordance with the Creative Commons Attribution 4.0 Unported (CC BY 4.0) license, which permits others to copy, redistribute, remix, transform and build upon this work for any purpose, provided the original work is properly cited, a link to the licence is given, and indication of whether changes were made. See: https://creativecommons.org/licenses/by/4.0/.

\section{ORCID iDs}

Gergő Baranyi http://orcid.org/0000-0002-3287-3629

Jamie Pearce http://orcid.org/0000-0002-0994-7140

\section{REFERENCES}

1 Vos T, Abajobir AA, Abate KH, et al. Global, regional, and national incidence, prevalence, and years lived with disability for 328 diseases and injuries for 195 countries, 1990-2016: a systematic analysis for the global burden of disease study 2016. Lancet 2017; 390: 1211-59.

2 McManus S, Bebbington P, Jenkins R, et al. Mental health and wellbeing in England: adult psychiatric morbidity survey 2014. Leeds, UK: NHS Digital, 2016.

3 Mental Health Foundation. Fundamental facts about mental health. London, UK: Mental Health Foundation, 2016

4 Richardson R, Westley T, Gariépy G, et al. Neighborhood socioeconomic conditions and depression: a systematic review and meta-analysis. Soc Psychiatry Psychiatr Epidemiol 2015:50:1641-56.

5 Gong Y, Palmer S, Gallacher J, et al. A systematic review of the relationship between objective measurements of the urban environment and psychological distress. Environ Int 2016;96:48-57

6 Baranyi G, Sieber S, Cullati S, et al. The longitudinal association of perceived neighborhood disorder and lack of social cohesion with depression among adults aged 50 and over: an individual participant data meta-analysis from 16 high-income countries. Am J Epidemiol 2019.

7 Kawachi I, Kennedy BP, Wilkinson RG. Crime: social disorganization and relative deprivation. Soc Sci Med 1999;48:719-31.

8 Bannister J, Bates E, Kearns A. Local variance in the crime drop: a longitudinal study of neighbourhoods in greater Glasgow, Scotland. Brit I Criminol 2018;58: 177-99

9 Kadra G, Dean K, Hotopf M, et al. Investigating exposure to violence and mental health in a diverse urban community sample: data from the South East London Community Health (SELCOH) survey. PLoS One 2014;9:e93660.

10 Lorenc T, Clayton S, Neary D, et al. Crime, fear of crime, environment, and mental health and wellbeing: mapping review of theories and causal pathways. Health Place 2012;18:757-65.

11 Bhavsar V, Boydell J, Murray R, et al. Identifying aspects of neighbourhood deprivation associated with increased incidence of schizophrenia. Schizophr Res 2014;156: $115-21$

12 Weisburd D, Cave B, Nelson M, et al. Mean streets and mental health: depression and post-traumatic stress disorder at crime hot spots. Am I Community Psychol 2018;61:285-95.

13 Beck A, Davidson AJ, Xu S, et al. A multilevel analysis of individual, health system, and neighborhood factors associated with depression within a large metropolitan area. J Urban Health 2017:94:780-90.

14 Astell-Burt T, Feng X, Kolt GS, et al. Does rising crime lead to increasing distress? Longitudinal analysis of a natural experiment with dynamic objective neighbourhood measures. Soc Sci Med 2015;138:68-73.

15 Dustmann C, Fasani F. The effect of local area crime on mental health. Econ J 2016;126:978.

16 Baranyi G, Cherrie M, Curtis S, et al. Neighborhood crime and psychotropic medications: A longitudinal data-linkage study of 130,000 Scottish adults. Am J Prev Med 2020;58:638-47.

17 Mair C, Diez Roux AV, Golden SH, et al. Change in neighborhood environments and depressive symptoms in New York City: the multi-ethnic study of atherosclerosis. Health Place 2015:32:93-8.

18 Blair A, Gariépy G, Schmitz N. The longitudinal effects of neighbourhood social and material deprivation change on psychological distress in urban, community-dwelling Canadian adults. Public Health 2015;129:932-40.

19 Ludwig J, Duncan GJ, Gennetian LA, et al. Neighborhood effects on the long-term well-being of low-income adults. Science 2012;337:1505-10. 
20 Brazil N, WAV Clark. Individual mental health, life course events and dynamic neighbourhood change during the transition to adulthood. Health Place 2017:45:99-109.

21 Jokela M. Does neighbourhood deprivation cause poor health? Within-individual analysis of movers in a prospective cohort study. J Epidemiol Community Health 2015;69:899-904.

22 Boyle PJ, Feijten P, Feng Z, et al. Cohort profile: the Scottish Longitudinal Study (SLS). Int J Epidemiol 2009;38:385-92.

23 Arthur A, Savva GM, Barnes LE, et al. Changing prevalence and treatment of depression among older people over two decades. Br J Psychiatry 2020;216:49-54.

24 Alvarez-Madrazo S, McTaggart S, Nangle C, et al. Data resource profile: the Scottish National Prescribing Information System (PIS). Int J Epidemiol 2016;45:714-5f.

25 Information Services Division, NHS National Services Scotland. Medicines used in mental health: years 2005/06 to 2015/16. National Statistics 2016. Available https:// www.isdscotland.org/Health-Topics/Prescribing-and-Medicines/Publications/201610-04/2016-10-04-PrescribingMentalHealth-Report.pdf (accessed 10 Dec 2019).

26 Information Services Division, NHS National Services Scotland. Hospital inpatient care of people with mental health problems in Scotland. National statistics 2017. Available https://www.isdscotland.org/Health-Topics/Mental-Health/Publications/2016-05-10/ 2016-05-10-MHIC-Report.pdf (accessed 10 Dec 2019).

27 Scottish Government. Scottish index of multiple deprivation (SIMD) 2012: technical notes. Scottish Government 2012. Available https://www2.gov.scot/Resource/0050/ 00504773.pdf (accessed 10 Dec 2019).

28 Scottish longitudinal study development \& support unit. SLS data dictionary. Available https://sls.Iscs.ac.uk/variables/ (accessed 10 Dec 2019).

29 Matthews JN, Altman DG, Campbell MJ, et al. Analysis of serial measurements in medical research. BMJ 1990;300:230-5.
30 Scottish Government. Scottish crime and justice survey 2017/18: main findings. National statistics 2019. Available https://www.gov.scot/publications/scottishcrime-justice-survey-2017-18-main-findings/ (accessed 10 Dec 2019).

31 Dohrenwend BP, Levav I, Shrout PE, et al. Socioeconomic status and psychiatric disorders: the causation-selection issue. Science 1992;255:946.

32 Simon GE, Coleman KJ, Yarborough BJH, et al. First presentation with psychotic symptoms in a population-based sample. Psychiatr Serv 2017;68:456-61.

33 Newbury JB, Arseneault L, Caspi A, et al. In the eye of the beholder: perceptions of neighborhood adversity and psychotic experiences in adolescence. Dev Psychopathol 2017;29:1823-37.

34 Fisher HL, Roberts A, Day F, et al. Impact of crime victimization on initial presentation to an early intervention for psychosis service and 18-month outcomes. Early Interv Psychiatry 2017;11:123-32.

35 Kondo MC, Andreyeva E, South EC, et al. Neighborhood interventions to reduce violence. Annu Rev Public Health 2018;39:253-71.

36 Braga AA, Turchan BS, Papachristos AV, et al. Hot spots policing and crime reduction: an update of an ongoing systematic review and meta-analysis. J Exp Criminol 2019;15:289-311.

37 Werner-Seidler A, Perry Y, Calear AL, et al. School-based depression and anxiety prevention programs for young people: a systematic review and meta-analysis. Clin Psychol Rev 2017;51:30-47.

38 Fusar-Poli P. Extending the benefits of indicated prevention to improve outcomes of first-episode psychosis. JAMA Psychiatry 2017;74:667-8.

39 Nossel I, Wall MM, Scodes J, et al. Results of a coordinated specialty care program for early psychosis and predictors of outcomes. Psychiatr Serv 2018, 69:863-70. 